\title{
Pag-asoy as a Tool in Developing the Students' Oral Language Fluency in the Classroom
}

\author{
Cristie Ann L. Jaca ${ }^{1, ~ *, ~ F e l i n o ~ B . ~ J a v i n e s ~ J r . ~}{ }^{1}$, Brian Anonat Vasquez ${ }^{2}$ \\ ${ }^{1}$ Department of Teacher Education, University of San Carlos, Cebu City, Philippines \\ ${ }^{2}$ Center for Research and Development, University of the Visayas, Cebu City, Philippines
}

\section{Email address:}

cristieann.ph@gmail.com (C. A. L. Jaca), afpressk12@gmail.com (F. B. J. Jr),3brianquez@gmail.com (B. A. Vasquez)

${ }^{*}$ Corresponding author

\section{To cite this article:}

Cristie Ann L. Jaca, Felino B. Javines Jr., Brian Anonat Vasquez. Pag-asoy as a Tool in Developing the Students' Oral Language Fluency in the Classroom. International Journal of Education, Culture and Society. Vol. 3, No. 5, 2018, pp. 86-91. doi: 10.11648/j.ijecs.20180305.12

Received: November 13, 2018; Accepted: November 27, 2018; Published: December 24, 2018

\begin{abstract}
This paper describes how pag-asoy (storytelling in Cebuano language) served as a tool in developing the students' oral fluency in their mother tongue. During the study period, the students were introduced to local Cebuano stories to determine their oral language fluency during classroom interaction. What was found out were the positive effects of using Cebuano folktales in promoting the Cebuano language during which pag-asoy was conducted. Using Cebuano stories told in Cebuano language provided an unequal impact to children because they can easily relate to the stories based on their personal experiences and emotional affiliations. Also, their effortless reactions allow them to use their first language confidently when they express their ideas and perspectives naturally like in a usual, casual conversation. Pag-asoy (Storytelling) in the mother tongue was found to solicit more class participation and oral interaction compared to stories told in English. As a result they develop oral fluency in their mother tongue (Cebuano) as they become expressive and participative as they listen to the story and to the information provided. Through pag-asoy children also enhanced the receptive skill of listening when they intently focus on the elements of the stories presented and actively participate in asking and answering questions during the pag-asoy.
\end{abstract}

Keywords: Oral Fluency, Mother Tongue, Pag-asoy, Storytelling, Cebuano Folktale

\section{Introduction}

One of the salient features of the $\mathrm{K}+12$ Enhanced Basic Education Program in the Philippines is building fluency in the mother tongue. The implementation of the Mother Tongue-Based Multilingual Education (MTBMLE) policy in $\mathrm{K}+12$ lists twelve Philippine languages to be used both as a medium of instruction (MOI) and as a learning area (Subject) from Kindergarten until Grade 3. DepEd Order No.16 series of 2012, lists 12 major Philippine languages (arranged alphabetically): Bikol, Cebuano, Chabacano, Hiligaynon, Iloko, Kapampangan, Maguindanaoan, Maranao, Pangasinense, Tagalog, Tausug, and Waray to be used as the Medium of Instruction (MOI) and as a learning area from Kindergarten until Grade three (3). Considered as the most widely spoken among these Philippine languages is the Cebuano language, popularly known as the Cebuano-Bisaya that makes use of the phonemic and orthographic letters of the Sinugbuanong Titikan (Cebuano Alphabet).

Among the fourteen Integrated Language Arts Domain in the $\mathrm{K}$ to 12 curriculum, Oral Language is given emphasis. Developing oral fluency in the students' L1 (Mother Tongue), L2 (Tagalog), and L3 (English) is the goal of the curriculum so students become functionally literate communicators who can use these languages in varied communication situations. According to Susan Malone, using L1 - especially oral L1 - in the classroom provides opportunities for parents and other community members who may not speak the school language to take an active role in their children's education [24]. The use of local stories in the classroom can encourage students' oral participation since they can talk about their own experiences in relation to the stories presented. This is where storytelling sessions prove to be helpful in introducing and building fluency in oral L1. Storytelling provides students a natural and spontaneous listening activity that allows them to interact and express themselves freely [21]. Thus, storytelling using local 
folktales can encourage students to develop appreciation of one's culture for stories provide a familiar context for exploration of social studies issues that students can relate to and can easily talk about [15]. Basa, a Cebuano Children's Literature writer, defines storytelling as an act of presenting to and sharing literature with others, which is considered as the oldest form of education other than learning by experience [3]. In effect, stories develop the student's language development and improvement. Likewise, Mason espoused that storytelling, by itself, is a valuable activity and serves a bridge to reading and writing [26].

While there are studies recognizing the benefits of storytelling for oral language development, comprehension, and appreciation of culture, these studies focus only on the effects of storytelling on the development of skills and not on the language used during storytelling and participation level of students when stories are presented [14, 28, 22]. However, there are no studies available on the use of Mother Tongue (particularly in Cebuano) as a storytelling medium during class discussions. To confirm whether the lingua franca is an effective tool in improving the students participation in class discussion, this comparative analysis of storytelling told in two different languages was explored (in L1 which is Cebuano, the students' mother tongue, and in L2 which is in English, the medium of instruction in school).

Pag-asoy is a local Cebuano word that is synonymous to storytelling in English. Culturally, it is a very personal way of narrating a story employing the human voice with a sense of emotion attached to the story as it is being told. It encompasses the different ways of telling stories including riddles, epics, legend, nursery rhymes and even folklores as part of oral tradition. It is a local way of presenting stories in a natural and spontaneous manner and is considered one of the most influential and traditional ways of preserving one's culture and heritage through oral transmission of ideas, thoughts, traditions, and history. Researchers believe that stories teach values and perpetuate culture and heritage as they are a vital form of communicating with people and society at large relaying messages, entertainment, knowledge and experiences and they bring meaning to life, convey values and emotions, and provide connection to our inner selves, with others and with society $[1,13,26]$. Children and adults who tell and listen to stories exercise the creative parts of their brains [14]. The effects of storytelling on oral language development, comprehension skills development and enhancing communicative skills highlighted the value of stories in motivating and improving the students' language abilities [22, 28, 31].

As there are limited literatures on multilingualism in the Philippines especially on the implementation of the MTBMLE as one of the key features of the $\mathrm{K}+12$ educational reform, it is then relevant to look into the implementation of mother tongue instruction to determine areas that needed improvement. The use of mother tongue as a medium of instruction and as a learning area especially in private schools has always been the topic of academic arguments during conferences and academic gatherings. This paper then provides an insight on the effects of mother tongue instruction and how it can improve the students' confidence in expressing themselves in the classroom.

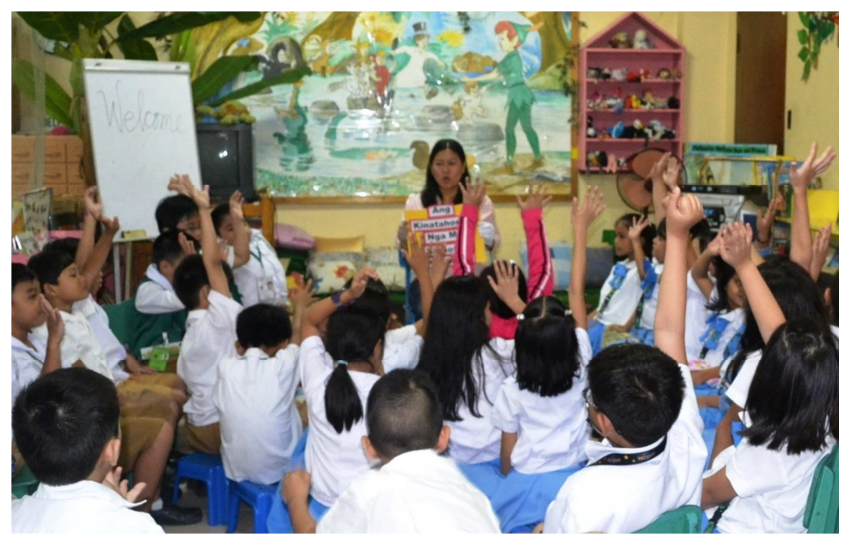

Figure 1. Pag-asoy Session.

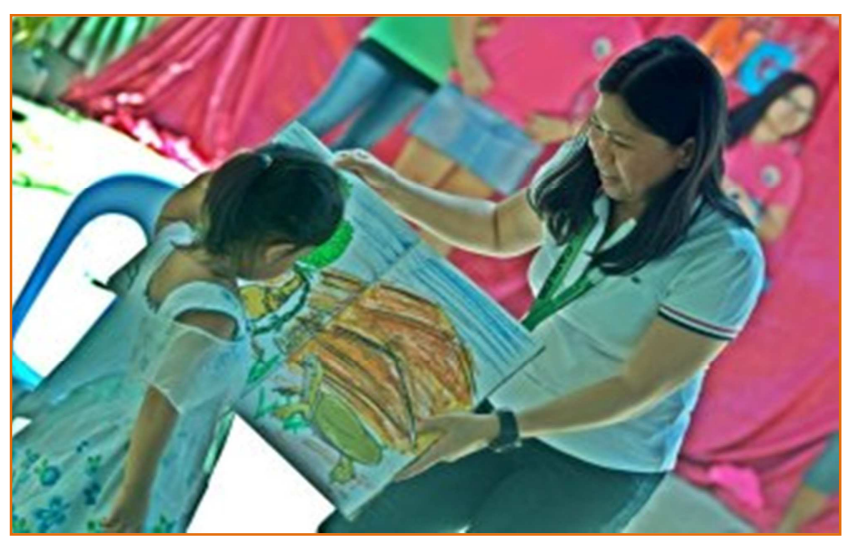

Figure 2. Pag-asoy Activity.

This paper presents how pag-asoy serves as a tool in developing the students' oral fluency in their mother tongue. It also presents the positive effects of using Cebuano folktales in promoting the local culture as it uses folktales told in Cebuano language during which pag-asoy (storytelling) was conducted. It provided an unequal impact to children because they can easily relate to the stories based on their personal experiences and the strong emotional attachment to the context of the story in their lives evidently noted.

\section{Method}

In this study, the cross-over non equivalent group design was used [30]. A crossover design is a repeated measurements such that each manipulated unit (class) be given different manipulations during the different time periods [29]. In this study, the class cross over from one manipulation to another during the course of the experiment. The reason to consider a crossover design is that it could yield a more efficient comparison of manipulations compared to a parallel design. Spontaneously, this appears equitable considering that each in the class serves as its own matched control considering that every class receives both $\mathrm{X}_{\mathrm{A}}$ and $\mathrm{X}_{\mathrm{B}}$ 
where a comparison is made of the subject's response on both manipulations.

The data were gathered from two Grade Two (3) classes (with 40 students per class) which were used as research subjects. These two classes have MTB subjects where they were taught content in the mother tongue which is in Cebuano. Pag-asoy (storytelling) was used as a motivation in engaging students to participate in class discussions. Using two local stories (Cebuano folktales) titled Nganong Mutuktugaok ang Sunoy (Why the Cock Crows) and Nganong Gidadala sa Pawikan ang Iyang Balay (Why the Turtle Carries Its House). These stories were told in two languages (Cebuano and English). The differences were noted based on the number of students who participated during the class discussion after the Pag-asoy (storytelling) was employed. During the storytelling sessions, between the two stories presented in Cebuano and in English, it was noted that there were more participation among the students when the stories were told in their mother tongue than in English.

Nominal counts were subjected to McNemer's Test to determine the difference between the dependent group testing.

\section{Results and Discussion}

Using storytelling as a method of story presentation, A Cebuano folktale titled Nganong Mutuktugaok ang Sunoy (Why the Cock Crows) was used as motivation in class. This was told in two languages, L1 in Cebuano and L2 in English. The comparative analysis determined in which language do students participate more in classes during classroom interaction.

Table 1. Cross-tabulation of participation between the use of Cebuano and English.

\begin{tabular}{|c|c|c|c|c|c|}
\hline \multirow{2}{*}{ Class } & & & \multicolumn{2}{|l|}{$\mathrm{X}_{\mathrm{B}}$ Story 2 - English } & \multirow{2}{*}{$\mathbf{N}$} \\
\hline & & & did not participate & participated & \\
\hline \multirow{2}{*}{ Class A } & Story $1-$ Bisaya $\mathrm{X}_{\mathrm{A}}$ & did not participate & 11 & 0 & 11 \\
\hline & Total & & 28 & 12 & 40 \\
\hline \multirow[b]{2}{*}{ Class B } & \multirow{2}{*}{ Story 1 - Bisaya $\mathrm{X}_{\mathrm{A}}$} & did not participate & 7 & 0 & 7 \\
\hline & & participated & 15 & 18 & 33 \\
\hline \multirow{3}{*}{ Total } & \multirow{2}{*}{ Story $1-$ Bisaya $\mathrm{X}_{\mathrm{A}}$} & did not participate & 18 & 0 & 18 \\
\hline & & participated & 32 & 30 & 62 \\
\hline & $\mathrm{N}$ & & 50 & 30 & 80 \\
\hline
\end{tabular}

Table 2. Cross-tabulation Summary of participation between the use of Cebuano and English.

\begin{tabular}{|c|c|c|}
\hline & $\mathrm{X}_{\mathrm{A}}$ Story 1 (Cebuano) & $\mathrm{X}_{\mathrm{B}}$ Story 2 (English) \\
\hline Class A (40 students) & 29 & 12 \\
\hline Class B (40 students) & 33 & 18 \\
\hline$\sum$ & 62 & 30 \\
\hline
\end{tabular}

Table 3. McNemar's Test Comparison between Storytelling in English and in Cebuano.

\begin{tabular}{lllll}
\hline $\mathbf{N}$ & $\mathbf{x}^{\mathbf{2}}$ & $\mathbf{p}$ & Decision & Interpretation \\
\hline 80 & 30.031 & 0.000 & Reject Ho & There is a significant difference in the participation of students in class between English and Cebuano \\
\hline
\end{tabular}

The table above reflects the results on what language do students participate more in class. It was found that when the story was told in English as a medium of instruction during storytelling, there was less participation and reaction from the students. However when pag-asoy (storytelling) in the mother tongue, which is Cebuano was used during the story presentation, the students were more participative and expressive as it gives natural and spontaneous reactions during the presentation as reflected in the chart above. Mokhtar and colleagues identified the effects of storytelling on students' language aspect of communication skills affirms the findings of this study that storytelling has beneficial effects on students expressive language skills as they can easily relate to the words and their meaning of the context which is not only familiar but also relevant to their personal experiences [28]. Likewise, the use of storytelling also helps in the development of the students' critical reading skills as students excitedly participate in answering comprehension questions after the pag-asoy (storytelling) [4]. Moreover, after the pag-asoy sessions, it was observed that students were able to appreciate local stories through the Cebuano folktales presented. Unconsciously, they improved their selfconfidence using their first language when explaining their opinions based on their vicarious and personal experiences. During pag-asoy, students were very attentive and were awed by the turn of events in the story. As a result, they were also very participative during the question and answer activity that almost everyone raises his/her hand to participate. Consequently, they become confident users of their mother tongue, the Cebuano language.

Differences in the two groups clearly indicate a higher participation level when storytelling was done in the mother tongue. It solicited more interaction compared to the one delivered in English. The observed high participation rate 
when the story was being delivered in Cebuano affirms the paper of Vasquez that students tend to mix both English and Cebuano-Visaya or even with Filipino-Tagalog when they socially and academically communicate [34]. Furthermore, Vasquez added that when teachers speak straight English in class, students had a hard time catching up with the inputs [34]. When the language used during discussions was modified allowing students to express in Cebuano-Visaya or in any language they are more comfortable, it was noticed that students: (1) were more able to explain their opinion; (2) began to interact with each other thru an intellectual debate; and (3) improved their academic performance. With this strategy, learning was much more effective. This is affirmed by Eladio C. Dioko when he highlighted this point in his paper that if students do not understand what the teacher is saying or what he reads in his books, learning does not occur [19]. He further claimed that the best medium of instruction should be the learner's own lingua franca. If the lingua franca is used: (1) learning is facilitated because concepts and ideas are readily understood; and (2) there is direct recognition of meaning.

The Department of Education, Culture and Sports promulgated Bilingualism Policy thru its Department Order No. 52, s.1987. "Bilingual Education aims at the achievement of competence in both Filipino and English at the national level, through the teaching of both languages and their use as media of instruction at all levels". The goals were to: (1) enhance learning through two languages to achieve quality education; (2) propagate Filipino as a language of literacy; (3) promote the development of Filipino as a linguistic symbol of national unity and identity; and (4) to cultivate and elaborate Filipino as a language of scholarly discourse.

Department of Education's Memorandum Order 74 series of 2009 mandates the Institutionalization of Mother TongueBased Multilingual Education (MTB-MLE) in all public and private elementary schools in the Philippines. Mother Tongue-Based Multilingual Education is the effective use of more than two languages for literacy and instruction. It can be implemented as a Medium of Instruction (MOI) or as a learning area (Subject) from Kindergarten to grade 1 and until Grade 3. MTB-MLE which refers to the use of the learners' mother tongue and two or more additional languages as Languages of Instruction (LoI) in school [23]. The official language policy of the 1987 Educational Act (revised in 2004) emphasized the use of first language for Grades 1 to 3 and then second language, which is English for grades 4 onwards. Many studies have already revealed that teaching using the mother tongue in the early grades enhances children's ability to learn better compared to the use of a second or foreign language (Skutnabb-Kangas, 2003 as cited by Rai and colleagues, 2011) [2, 32, 33]. Likewise, Carol Benson, in her research, concluded that mother tonguebased bilingual education also raises the superiority of basic education by facilitating classroom interaction and integration of prior knowledge and experiences with new learning [5]. She further explained that the effects of bilingual schooling depict the progress made by traditionally marginalized students in the process of: (1) becoming literate in a familiar language; (2) gaining access to communication and literacy skills in the second or third language; (3) having a language and culture that are appreciated and respected by formal institutions like the school; (4) feeling good and comfortable about the school and the teacher; (5) being able and even encouraged to demonstrate what they know; (6) participating in their own learning; (7) having the courage to ask questions in class or ask the teacher what is being done; (8) attending school and having an improved chance of succeeding; and (9) not being taken advantage of.

However, the researchers did not impose that classes be delivered in lingua franca. There is still a need to use English as a medium of communication to prepare the students to be globally competitive. However, the researchers find the need to promote the use of both English and the lingua franca in the curriculum. This gives a competitive advantage to the students in the classroom. This is affirmed by Villanueva and Almario claiming that bilingual classrooms do more than just preserve national identity, it also result in numerous benefits on the part of the learner [35]. They further stressed that educators and educational researchers should endeavor to work towards making bilingual learning systematic and effective. Bernardo and Gaerlan claimed that bilinguals and multilinguals tend to develop interesting cognitive learning processes $[6,7,12]$. Bialystok and colleagues established in their researches that bilinguals and multilinguals have heightened their executive control skills and perform better in various learning tasks, including non-verbal problem solving compared to monolinguals $[8-11,20,25]$. The executive control skills mentioned have 8 pillars according to Cox: (1) initiation; (2) flexibility; (3) attention; (4) organization; (5) planning; (6) working memory; (7) self-awareness; and (8) regulating emotions [17]. These were all related to selectivediscerning attention that is very important in learning and performing multifarious tasks.

Pag-asoy (storytelling) is an effective means of building rapport between the teacher and the students and among students in class [13-15, 26-28, 31]. Storytelling in the mother tongue provides opportunities for students to find meaning in what they are learning as stories are the bridges between the individual experience and social patterns [1, 4, 19, 34]. As a result, students get to participate in class discussions as they are free to express themselves in a language they are most confident and comfortable using, their mother tongue. Cebuano-Bisaya as the lingua franca in the region is popularly used when sharing experiences especially using stories.

\section{Conclusion}

Pag-asoy (storytelling) sessions using Cebuano folktales and presented using the Cebuano language have provided positive effects on the students' oral language development as reflected in their participation index. The positive feedback increased the students' oral participation and made them use their mother tongue in talking and sharing about 
what they already know and experienced in their own speech community which also revealed their cultural background. Through pag-asoy, students have developed oral fluency in the mother tongue, enhanced their confidence in class as they expressed their reactions spontaneously, and improved their receptive skill in listening as stories told in their mother tongue lead to a more personal and familiar understanding of their culture as it is related to their own context and way of life. Consequently, it made the students become more engaged during class time as they participate more during classroom discussions through answering questions and asking questions themselves.

\section{References}

[1] Atkinson, R. (2002). The life story interview. In Gubrium, J. F., \& Holstein, J. A. (Eds). Handbook of interview research: Context and method. SAGE Publications, Thousand Oaks CA. pp. 21-140.

[2] Ball, J. (2011). Enhancing learning of children from diverse language backgrounds: Mother tongue-based bilingual or multilingual education in the early years. France: UNESCO.

[3] Basa, J. V. (1991). Teach and enjoy children's literature: A handbook of modules. Cebu City.

[4] Belet, D. , \& Dal, S. (2010). The use of storytelling to develop the primary school students' critical reading skill: The primary education pre-service teachers 'opinions. Procedia Social and Behavioral Sciences, 9(1), 1830-1834.

[5] Benson, C, (2004). The importance of mother tongue-based schooling for educational quality. The Quality Imperative: Education for All Global Monitoring Report 2005.

[6] Bernardo, A. B. I. (2005). Bilingual code-switching as a resource for learning and teaching: Alternative reflections on the language and education issue in the Philippines. In Dayag, D. T. , \& Quakenbush, J. S. (Eds.), Linguistics and language education in the Philippines and beyond: A Festschrift in honor of Ma. Lourdes S. Bautista. Manila: Linguistic Society of the Philippines. pp. 151-169.

[7] Bernardo, A. B. I., \& Gaerlan, M. J. M. (2011). Non-native English students learning in English: Reviewing and reflecting on the research. In Jaidev, R., Sadorra, M. L. C., Wong, J. O., Lee, M. C., \& Lorente, B. P. (Eds.), Global perspectives, local initiatives: Reflections and practices in ELT. Singapore: National University of Singapore, Centre for English Language Communication. pp.1-9.

[8] Bialystok, E. (2007). Cognitive effects of bilingualism: How linguistic experience leads to cognitive change. International Journal of Bilingual Education and Bilingualism, 10, 210-223.

[9] Bialystok, E. (2010). Global-local and trail-making tasks by monolingual and bilingual children: Beyond inhibition. Developmental Psychology, 46, 93-105.

[10] Bialystok, E., \& Majumder, S. (1998). The relationship between bilingualism and the development of cognitive processes in problem solving. Applied Psycholinguistics, 19, 69-85.

[11] Bialystok, E., Craik, F., \& Luk, G. (2008). Cognitive control and lexical access in younger and older bilinguals. Journal of
Experimental Psychology: Learning, Memory, and Cognition, 34, 859-873.

[12] Blot, K. J., Zarate, M. A., \& Paulus, P. B. (2003). Codeswitching across brainstorming sessions: Implications for the revised hierarchical model of bilingual language processing. Experimental Psychology, 50(1), 171-180.

[13] Bowles, N. (1995) Storytelling: a search for meaning within nursing practice. Nurse Education Today, 15(5), 365-369.

[14] Brand, S. T. , \& Donato, J. M. (2001). Storytelling in emergent literacy: Fostering multiple intelligences. Albany, NY: Delmar-Thomson. bridging languages in MTB MLE programs, Bangkok.

[15] Combs, M., \& Beach, J. (1994). Stories and storytelling: Personalizing the social studies. The Reading Teacher, 47(6), 464-471. Retrieved October 18, 2018 from http://www.jstor.org/stable/20201292

[16] Constitution of the Republic of the Philippines (1987).

[17] Cox, A. J. (2007). No mind left behind: Understanding and fostering executive control - the eight essential brain skills every child needs to thrive. New York: Penguin Group.

[18] Department of Education, Culture and Sports (1987). Bilingualism. Diliman, Quezon City: The University of the Philippines Press.

[19] Dioko, E. C. (2007). Basic education - The language issue. The Green and White Journal, 2 (1), pp.15-26.

[20] Emmorey, K., Luk, G., Pyers, J. E., \& Bialystok, E. (2008). The source of enhanced cognitive control in bilinguals: Evidence from bimodal bilinguals. Psychological Science, 19(2), 1201-1206. doi:10.1111/j.1467-9280.2008.02224.x

[21] Grugeon, E., \& Gardner, P. (2000). The art of storytelling for teachers and pupils: Using stories to develop literacy in primary classrooms. London: David Fulton.

[22] Isbell, R., Sobol, J., Lindauer, L., \& Lowrance, A. (2004). The effects of storytelling and story reading on the oral language complexity and story comprehension of young children. Early Childhood Education Journal, 32(1), 157-163.

[23] Lartec, J. K., Belisario, A. M., Bendanillo, J. P., Binas-o, H. K., Bucang, N. O., \& Cammagay, J. L. W. (2014). Strategies and Problems Encountered by Teachers in Implementing Mother Tongue-Based Instruction in a Multilingual Classroom. IAFOR Journal of Language Learning, 1(1). http://ezproxy.usc.edu.ph/login?url=http://search.ebscohost.co $\mathrm{m} /$ login asp $x$ ?direct $=$ true $\& \mathrm{db}=$ eric $\& \mathrm{AN}=\mathrm{EJ} 1167236 \&$ site $=\mathrm{ed}$ s-live

[24] Malone, S. (2012). Introducing and building fluency in oral and written L1. Workshop on bridging languages in MTB MLE programs, Bangkok.

[25] Martin-Rhee, M. M., \& Bialystok, E. (2008). The development of two types of inhibitory control in monolingual and bilingual children. Bilingualism: Language and Cognition, $11,81-93$.

[26] Mason, H. (1996). The power of storytelling: A step-by-step guide to dramatic learning in K-12. California: Corwin Press, Inc., SAGE Publications Inc.

[27] Mellon, N. (1993). The art of storytelling. Australia: Element Books Limited. 
[28] Mokhtar, N. H., Halim, M. F. A., \& Kamarulzaman, S. Z. S. (2011). The Effectiveness of Storytelling in Enhancing Communicative Skills. Procedia - Social and Behavioral Sciences, $\quad 18(1), \quad 163-169 . \quad$ DOI: https://doi.org/10.1016/j.sbspro.2011.05.024

[29] PennState Eberly College of Science, 2018. Lesson 15: Crossover Designs of STAT 50 Design and Analysis of Clinical Trials. Retrieved October 21, 2018 from https://onlinecourses.science.psu.edu/stat509/node/123/

[30] Polit, D. F. , \& Beck, C. T. (2008). Nursing research: Generating and assessing evidence for nursing practice (8th Ed.). Philadelphia, PA: Wolters Kluwer Health/Lippincott Williams \& Wilkins.

[31] Powell, R. M. , \& Murray, O. (2012). Using storytelling strategies to improve student comprehension in online classes. The Journal of Effective Teaching, 12(1), 46-52. Publishers Ltd.

[32] Rai, V., Rai, M., Phyak, P., Rai, N. (2011). Multilingual education in Nepal: Hearsay and reality? Kathmandu: United Nations Educational, Scientific and Cultural Organization Office.

[33] Trudell, B. (2016). The impact of language policy and practice on children's learning: Evidence from Eastern and Southern Africa. Retrieved from UNICEF.http://www.unicef.org/esaro/UNICEF (2016)LanguageandLearning-FullReport (SingleView).pdf.

[34] Vasquez, B. A. (2013). Politico-economic influence and social outcome of English language among Filipinos: An autoethnography. University of the Visayas Journal of Research, 7(1), 183-193.

[35] Villanueva, A. J. R., \& Almario, A. R. S. (2008). Dual language program models in Philippine progressive schools. Paper presented at the 2nd international conference on language development, language revitalization, and multilingual education in ethonolinguistic communitites, Bangkok, Thailand.

\section{Biography}

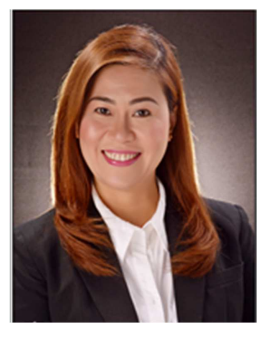

Cristie Ann L. Jaca, PhD is an Associate Professor of the University of San Carlos in Cebu City, Philippines. She taught high school for two years and has been teaching in the university for twenty two years handling English language subjects, professional education courses, curriculum, and research subjects in both undergraduate and graduate programs of the same university. She was the former Chair of the Department of Teacher Education in the University of San Carlos, Academic Years 2014-2016. She was also the Head of the English Language Section of the Department of Languages and Literature of the same university during Academic Years 2008-2010. She is a teacherresearcher who embraces the challenges and opportunities of $21^{\text {st }}$ century teaching and learning through engaging in research and publication that can improve her teaching practice.

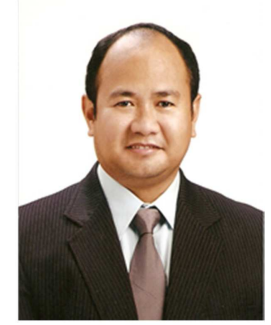

Felino B. Javines Jr., SVD, DM is a Graduate Professor of the University of San Carlos and Cebu Normal University in Cebu City, Philippines. He was the former Director of the University of San Carlos, Basic Education Department. He is the architect of the Collaborative Senior High School Program. He is an accreditor of Philippine Association of Accrediting Colleges and Universities (PAASCU) and likewise a Senior High School National Trainer under Philippine Education Assistance Committee (PEAC). As advocate of competency based senior high school programs, he is an active member of Regional Association for Vocational Teacher Education (RAVTE).

Brian Anonat Vasquez, RN, PhD is the Research Director of the University of the Visayas, Cebu City, Philippines. Brian earned his Bachelor of Science in Psychology from the University of San Carlos in 2002 and Bachelor of Science in Nursing from the University of the Visayas in 2005. He received his Master of Arts in Nursing, Major in Medical Surgical Nursing in 2009 from the University of the Visayas where he also obtained additional masteral units in Guidance and Counseling, and Nursing Management. He graduated with the Best Thesis Award and received commendation from the Philippine Association for Graduate Education - Region VII. He obtained his Doctor of Philosophy in Education, Major in Research and Evaluation from Cebu Normal University. He has the passion for Cultural Health and Education Studies, Quality Management System, and Lean Sigma Methodologies. 